
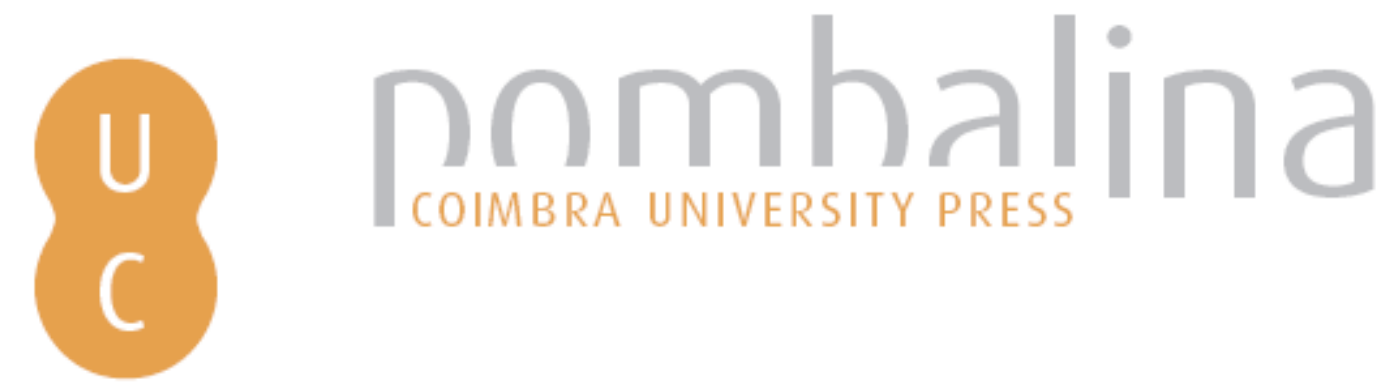

\title{
Poética Comparada: el teatro griego clásico en la Postdictadura: Esquilo en las reescrituras y la concepción de Daniel Casablanca
}

\author{
Autor(es): Dubatti, Jorge
}

Publicado por: Imprensa da Universidade de Coimbra

URL

persistente: URI:http://hdl.handle.net/10316.2/43007

DOI: $\quad$ DOI:https://doi.org/10.14195/9789892614397_27

Accessed : $\quad$ 26-Apr-2023 09:30:37

A navegação consulta e descarregamento dos títulos inseridos nas Bibliotecas Digitais UC Digitalis, UC Pombalina e UC Impactum, pressupõem a aceitação plena e sem reservas dos Termos e Condições de Uso destas Bibliotecas Digitais, disponíveis em https://digitalis.uc.pt/pt-pt/termos.

Conforme exposto nos referidos Termos e Condições de Uso, o descarregamento de títulos de acesso restrito requer uma licença válida de autorização devendo o utilizador aceder ao(s) documento(s) a partir de um endereço de IP da instituição detentora da supramencionada licença.

Ao utilizador é apenas permitido o descarregamento para uso pessoal, pelo que o emprego do(s) título(s) descarregado(s) para outro fim, designadamente comercial, carece de autorização do respetivo autor ou editor da obra.

Na medida em que todas as obras da UC Digitalis se encontram protegidas pelo Código do Direito de Autor e Direitos Conexos e demais legislação aplicável, toda a cópia, parcial ou total, deste documento, nos casos em que é legalmente admitida, deverá conter ou fazer-se acompanhar por este aviso.

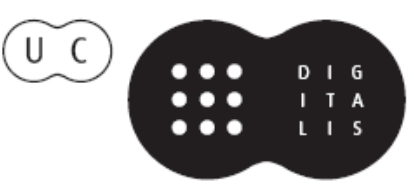




\section{Pervivencia del mundo clásico en la literatura:}

\section{tradición y relecturas}

\section{Aldo Rubén Pricco, Stella Maris Moro (coords.)}

IMPRENSA DA UNIVERSIDADE DE COIMBRA 


\title{
Pó́tica Comparada: \\ el teatro griego clásico en la Postdictadura. Esquilo en las reescrituras y la concepción de Daniel Casablanca (Comparative Poetics: the classical Greek theater in the Post-dictatorship. Aeschylus in rewrites and the conception of Daniel Casablanca)
}

\author{
Jorge Dubatti (jorgeadubatti@hotmail.com) \\ Facultad de Filosofía y Letras - Universidad de Buenos Aires
}

Resumen - La productividad del teatro griego clásico constituye una constante en la dramaturgia y la escena argentinas, desde sus orígenes y especialmente en el período de la Postdictadura (1983-2014). En este contexto, caracterizado por la diversidad de las prácticas micropoéticas y el auge del canon de la multiplicidad (o canon imposible), se destaca el trabajo de Daniel Casablanca (Buenos Aires, 1965) con las tragedias de Esquilo. Reconocido actor cómico, Casablanca ha dirigido seis puestas en escena de tragedias de Esquilo: Prometeo (versión de Prometeo encadenado, 2002-2003), Los Persas (2004), Las Suplicantes (2005), Sitiados (versión de Los Siete contra Tebas, 2007), Las Suplicantes (2010-2011) y Prometeo en trance (versión de Prometeo encadenado, 2011). Este artículo focaliza en la concepción directorial de Casablanca, a través de una entrevista realizada en 2007, desde la perspectiva de la Poética Comparada, disciplina que pone el acento en que los vínculos inter-territoriales, inter-culturales e inter-lingüísticos generan procesos de reescritura. La aproximación a las versiones de Casablanca de los textos de Esquilo impone una perspectiva: no se trata de buscar la "fidelidad" o el "respeto" a los textos-fuente, sino por el contrario percibir diferencias, apropiaciones, mezclas y sincretismos, nuevos procedimientos y significaciones en la triple dimensión del análisis de la poética: estructura - trabajo - concepción.

Palabras clave: Esquilo, Daniel Casablanca, Buenos Aires, reescritura teatral, Postdictadura.

Aвstract - The productivity of the classical Greek theater is a constant in Argentine dramaturgy and the scene, from its origins and especially in the period of the Post-dictatorship (1983-2014). In this context, characterized by the diversity of micropoetic practices and the rise of the canon of multiplicity (or impossible canon), Daniel Casablanca (Buenos Aires, 1965) stands out with his work on the tragedies of Aeschylus. A well-known comic actor, Casablanca has directed six scenarios of Aeschylus' tragedies: Prometheus (version of Prometheus bound, 2002-2003), The Persians (2004), The Supliants (2005), Besieged (version of The Seven against Thebes, 2007), The Suppliants (2010-2011) and Prometheus in trance (version of Prometheus bound, 2011). This paper focuses on the directorial conception of Casablanca, through an interview conducted in 2007, from the perspective of Comparative Poetics, a discipline that stresses that inter-territorial, inter-cultural and inter-linguistic relations generate processes of rewriting. The approach to the Casablanca versions of the texts of Aeschylus imposes a perspective: it is not a question of seeking "fidelity" or "respect" 
to the source-texts, but instead perceiving differences, appropriations, mixtures and syncretisms, new procedures and significations in the triple dimension of the analysis of poetics: structure - work - conception.

Keywords: Aeschylus, Daniel Casablanca, Buenos Aires, theatrical rewriting, Post-dictatorship

La productividad del teatro y la cultura clásicos constituye una constante en la dramaturgia y la escena argentinas, desde sus orígenes, en todo el trayecto de su historia y especialmente en el período de la Postdictadura (1983-2014) ${ }^{1}$. Algunos de los hitos fundamentales del teatro nacional en los últimos treinta años parten-directa o indirectamente- del mundo grecolatino antiguo, ya sea a través de la recreación de mitos, la adaptación escénica de textos literarios clásicos, la intertextualidad o la puesta en escena de comedias y tragedias clásicas.

Baste mencionar sólo algunos casos notables del teatro de Buenos Aires seleccionados entre decenas de espectáculos: Antígona furiosa (1986) de Griselda Gambaro; La historia del tearto (sic) (1989) por El Clú del Claun; la reescritura de Antígona de Sófocles, dirigida por Alberto Ure (1989); el mito del Minotauro en Asterión (1991) de Guillermo Angelelli; la adaptación de Las aves de Aristófanes en Salto al cielo (1991) de Mauricio Kartun; el mito de Orfeo en La casa sin sosiego (1992), ópera de cámara de Griselda Gambaro y Gerardo Gandini; la reescritura de la Orestíada de Esquilo en La oscuridad de la razón (1994) de Ricardo Monti, y de Edipo Rey de Sófocles en Zooedipous (1998) del Periférico de Objetos; la experiencia performativa Filoctetes realizada en las calles de Buenos Aires bajo la dirección de Emilio García Wehbi (2001); la versión de Electra Shock (2005), a partir del texto de Sófocles, dirigida por José María Muscari; Lisistrata Unplugged (2007) de Andrés Sahade, a partir de la comedia de Aristófanes; Prometeo. Hasta el cuello (2008), con dirección de Diego Starosta; Medea (2009) de Eurípides, protagonizado por Cristina Banegas y dirección de Pompeyo Audivert.

En este contexto, signado por la diversidad de las prácticas micropoéticas y el auge del canon de la multiplicidad (o canon imposible) ${ }^{2}$, se destaca el trabajo de Daniel Casablanca con las tragedias de Esquilo.

Daniel Casablanca es uno de los más grandes actores cómicos de la Argentina y, paradójicamente, quien más sistemáticamente se ha vinculado a las tragedias de Esquilo, como director, desde el 2002 y hasta el presente. Intérprete ampliamente conocido y varias veces premiado, Casablanca es miembro fundador de la Banda de Teatro Los Macocos (nacida en 1985 y aún en actividad),

\footnotetext{
${ }^{1}$ Remitimos a los resultados de la investigación "El imaginario clásico en la dramaturgia argentina de la Postdictadura: relevamiento de textos y estado actual de la investigación”, radicada bajo nuestra dirección desde 2005 en el Centro de Investigación en Historia y Teoría Teatral, CIHTT, UBA, en la que participan las profesoras Cristina Quiroga y Natacha Koss.

${ }^{2}$ Véanse sobre el período de la Postdictadura Dubatti 2002, 2003, 2006, 2015.
} 
grupo fundamental en la historia de la renovación teatral argentina después de la dictadura, con el que ha estrenado más de quince producciones ${ }^{3}$. Paralelamente a su trabajo en Macocos, desde 1988 desarrolla una amplia tarea como actor profesional, siempre en roles cómicos y contratado por las grandes salas oficiales. Para el Teatro San Martín o el Complejo Teatral de Buenos Aires, Casablanca ha realizado -entre muchos- personajes centrales de La tempestad de Shakespeare (dir. Claudio Hochman, 1997-1999), Sueño de una noche de verano de Shakespeare (dir. Alicia Zanca, 2005), Arlequin servidor de dos patrones de Carlo Goldoni (dir. Alicia Zanca, 2007) y Toc toc de Laurent Baffie (dir. Lía Jelín, 2011-2014 y continúa con éxito en el circuito comercial). Casablanca estudió en la Escuela Nacional de Arte Dramático (1984-1987) y con Los Volatineros en la Escuela del Parque (1985-1988). Luego se formó con Cristina Moreira, a través de quien tomó contacto con los métodos de Jacques Lecoq y Philippe Gaulier y practicó sistemáticamente en las materias Tragedia, Bufón, Clown y Máscara Neutra. También realizó un taller intensivo de clown con Raquel Sokolowicz. Ya en 1988 fundó su escuela de teatro, con un programa de estudios que consiste en tres niveles de cursos anuales ( $1^{\circ}$ Nivel: Introducción a los juegos teatrales; $2^{\circ}$ Nivel: Géneros: tragedia, bufón y esencia; $3^{\circ}$ Nivel: Creación colectiva y realización de un espectáculo). Prepara actualmente un libro, Escuela Casablanca. Método del Actor Creador, en el que ilustra los principios de su pedagogía y su pensamiento teatral, una suerte de Filosofía de la Praxis de gran originalidad. Con elencos surgidos de la Escuela Casablanca ha estrenado hasta hoy una veintena de espectáculos. Pero además ha dirigido numerosos espectáculos en otros circuitos: Alma de Saxofón (Grupo Cuatro Vientos) (1997, 1er Festival Internacional de Teatro de la Ciudad de Buenos Aires); 44 atardeceres, espectáculo basado en El Principito de Saint-Exupéry (2000, Auditorio de la Alianza Francesa y gira por todo el país); Cenicienta la historia continúa, espectáculo infantil (2000, Teatro Maipo); Forever Young (2012, Teatro Picadero y numerosas reposiciones) de Eric Gedeon. Realizó además la dirección actoral y colaboración artistíca de Hermosura, producción del grupo El Descueve.

Entre 2002 y 2011, con alumnos de su escuela y actores profesionales, $\mathrm{Ca}$ sablanca ha puesto en escena espectáculos centrados en versiones de las tragedias de Esquilo. No se trata de meras muestras de fin de curso con alumnos, sino de espectáculos completos, que integraron la cartelera porteña y estuvieron abiertos al público en temporada.

Las fichas técnicas completas de los espectáculos de la serie dedicada a Esquilo son:

${ }^{3}$ Para la historia de Macocos sugerimos la consulta de nuestro estudio preliminar a Teatro deshecho I. Flora y fauna de la creación macocal, de Los Macocos Banda de Teatro (2002: 5-51). 
Prometeo

Versión de Prometeo encadenado

Elenco: Rodrigo Bello, Daniel Campomanesi, Marcelo Cioffi, Walter Iapeghino, Yamila Kargieman, Julio Martinez, Adriana Sagabache, Ana Said, María José Salvo, Mariana Vidal, Alejandro Zanga Entrenamiento actoral: César Lerner

Entrenamiento vocal: Marcelo Xicarts

Asistencia de dirección: Andrés Sahade

Dirección: Daniel Casablanca

2002 - IFT (espacio debajo del escenario de la Sala Grande, Boulogne Sur Mer 549)

2003 - Sala E1 Gato Viejo (Avenida del Libertador 405, y Suipacha)

\section{Los Persas}

Versión de la tragedia homónima

Elenco: Daniel Campomenosi, Julia Cavagna, Dolores Escardó, Mathías Florencio, Marisa González, Chula - Chechi, Natalia Sánchez, Gusty

Dirección: Daniel Casablanca

2004 - El Ombligo de la Luna (Anchorena 364)

\section{Las Suplicantes}

Versión de la tragedia homónima

Elenco: Gonzalo Amor, Lucía Ballefin Benites, Guadalupe Bervih, Gabriela Biebel, Julio Graham, Gustavo Iapeghino, Claudia Tassano Eckart

Diseño de maquillaje: Daniela Sitnisky

Entrenamiento vocal: Marcelo Xircats

Asistencia de dirección: Andrés Sahade

Dirección: Daniel Casablanca

2005 - IFT

\section{Sitiados}

Versión de Los siete contra Tebas

Dramaturgia: Federico Ara, Daniel Casablanca

Elenco: Federico Ara, Karina Arazi, María Eugenia Berenc, Mercedes Candegabe, Verónica Cohen, Déborah Mariño, Lucila Perugini, Lucía Pochat, Germán Ruccella, Andrés Serebrenik, Alejandra Tuculet

Asistencia de dirección: Gabriela Biebel, Andrés Sahade

Dirección: Daniel Casablanca

2007 - Absurdo Palermo (Ravignani 1557) 
los años de Post-dictadura, relacionable a su vez con otras categorías de dramaturgia, por ejemplo, de dirección y de actuación. Reescribir implica recuperar los valores (narrativos, morfológicos, fonéticos, semánticos, lingüísticos, etc.) del texto previo, pero también implementar sobre él una política de la diferencia, vinculada a la nueva territorialidad y a la percepción del tiempo presente.

Una primera aproximación a las versiones de Casablanca a partir de los textos de Esquilo impone una perspectiva: no la de quien busca la confirmación, la "fidelidad" o el "respeto" a los textos de Esquilo, sino por el contrario la de quien está dispuesto a percibir diferencias, apropiaciones, mezclas y sincretismos, nuevos procedimientos y significaciones. Interesa saber cómo el texto-destino reelabora, fusiona, hibridiza culturas, estados del teatro, territorialidades, poéticas y concepciones. Por otra parte, cómo intervienen en la constitución de una nueva poética las técnicas y el entrenamiento de los actores en cuyo trabajo se materializa el acontecimiento teatral.

Para comprender esos procesos de reescritura, entendidos como formas de apropiación, re-poetización y re-significación, en la triple dimensión del análisis de la poética: estructura - trabajo - concepción (Dubatti, 2010: 117-152), la entrevista con el director y el acceso a su archivo son de suma utilidad para la investigación. En ellos nos centraremos.

\section{ESQUILO Y “LAS ZONAS PERDIDAS DEL TEATRO”}

¿Por qué el interés por la tragedia en un actor cómico devenido director? Según nos explicó Daniel Casablanca en una entrevista ${ }^{4}$,

Disfruté mucho cuando estudié tragedia con Cristina Moreira, aunque seguramente la gente se reía de mi actuación... Como mi instrumento no da para el género, lo disfruto como docente y director. Dicto tragedia a los alumnos de segundo año, después de un año de juego teatral. Para los alumnos ahora el protagonismo no es del juego sino del texto. Esquilo es el centro absoluto. No puede haber tanto juego físico porque eso estaría compitiendo con la importancia del texto.

¿Por qué Esquilo y no Sófocles o Eurípides, mucho más representados que Esquilo en la escena argentina? Casablanca propone una perspectiva inesperada, sin duda articuladora de la concepción de sus puestas en escena:

Esquilo es el más puro, el más mágico. Se diferencia de Sófocles y Eurípides, que son mucho más 'modernos' y más viejos al mismo tiempo. Leo a Sófocles y a Eurípides y tienen algo de películas viejas. Esquilo entra en otra

${ }^{4}$ Realizada por el autor de este artículo en Buenos Aires en sucesivos encuentros durante el mes de julio de 2007 . 
categoría: casi no es teatro. Está más cerca del ritual. Además encarna los grandes lamentos del hombre. La información narrativa es pequeña, entonces todo lo que queda es puro teatro. Es poco intelectual, es muy visceral. Esquilo me permite recuperar zonas perdidas del teatro, un teatro puro. Tal vez suene ingrato con Sófocles, pero recién poniendo en escena Los siete contra Tebas entendí Antígona. Sófocles viene de allí: seguramente se inspiró en Esquilo para escribir Antígona. Esquilo es el creador de la gran convención del teatro.

Frente a estas afirmaciones, que se apropian de la figura y el legado de Esquilo con absoluta libertad, cabe preguntarse: ¿qué sabe Casablanca de Esquilo, qué ha estudiado? Casablanca contesta, poniendo en evidencia el valor de la apropiación desde una nueva concepción, sin duda anclada en una nueva historicidad y territorialidad, la de Buenos Aires en el siglo XXI:

Que fue un guerrero, se nota que escribe como un militar. No un militar argentino ni americano, sino un héroe clásico. Sé que por lo que escribió se tuvo que ir de Grecia. Fue un héroe de guerra y termina su vida desterrado en Creta a causa de sus obras. Esquilo tiene algo de brujo, de sacerdote de ditirambo. Tiene algo de Don Genaro, el bailarín de Carlos Castaneda [Relatos de poder, 1975], algo de chamán. Los textos de Esquilo tienen magia antropológica. Cuando les doy los textos de Esquilo a mis alumnos y los leen, se ríen, me dicen que estoy loco. Pero cuando el cuerpo se pone en movimiento desde las grandes energías hieráticas, o desde los grandes fenómenos naturales, cuando el fuego, los grandes ríos rápidos o el hielo dicen estos textos, la magia es inconmensurable.

Según Casablanca, "para el espectador actual no es fácil entrar en la convención de Esquilo. Es una experiencia religiosa a la que la gente entra con mucha resistencia. Al principio aparecen los chistes y las risitas, pero cuando se instala el código no tiene pausa”.

La tragedia tiene una zona de opresión y ahogo muy grande, pero en un momento ingresa en una zona de liberación. Nadie quiere vivir tragedias, todo el mundo prefiere escapar, pero también es catártico. Es muy sanador. La comedia pasatista es más fácil, pero no deja nada. No tiene riesgo para el espectador. El artista apuesta a arriesgar para que el espectador arriesgue con él. Para que el espectador no actúe de espectador. Desafío y riesgo. La tragedia es liberadora pero hay que bancársela.

Esquilo siempre te representa: una tragedia que hayas vivido, un dolor muy grande que estés transitando, el dolor de un país, un acontecimiento importante en el mundo. Se relaciona con los grandes lamentos, catástrofes, infortunios del hombre. No hay manera de quedar afuera. Si pasás la etapa de resistencia. Cuando hicimos Los sitiados [reescritura de Los Siete contra Tebas] 
todo el tiempo yo sentía la imagen de las Torres Gemelas. No es una idea impuesta: conectaba el dolor.

Le preguntamos por la naturalización de la tragedia en los medios masivos, que a cada rato en los noticieros muestran tragemas (en el sentido que Jan Kott otorga al término) y esto implica una insensibilización: ¿por qué regresar a la tragedia clásica, qué más trágico que la realidad? "La tragedia es un hecho poético y sanador, en cambio la realidad es trivial -afirma Casablanca. Los noticieros banalizan, la tragedia otorga sentido, construye sentido. Ir al teatro es un acto religioso".

Por otra parte, "Esquilo propone una invocación a los muertos", asegura el director, y ello lo conecta con una tendencia potente en la escena argentina contemporánea: el teatro de los muertos (Dubatti, 2014: 137-164).

Para Casablanca es fundamental la reescritura como nuevo territorio inter-cultural, inter-territorial, inter-histórico, en tanto "la adaptación consiste en liberar el texto de aquellas cosas que no tienen sentido para un espectador común. Esquilo es mucho más fácil de adaptar porque tiene una síntesis enorme”.

Adaptar es establecer cruces con la contemporaneidad, puentes con el tiempo más próximo. Buscar una imagen más heterogénea. Ambienté Los sitiados en la década del 40, en la guerra, y los convertí en una familia judía. El camino hacia la profundización de la tragedia es humanizarla. La tragedia es dura y resulta indispensable que el espectador pueda familiarizarse con ese mundo.

En el programa de trabajo de Casablanca está estrenar las siete tragedias conservadas. ¿Por qué el ciclo completo?

Porque sigo descubriéndolo. Cuando hice la primera tragedia no sabía a dónde iba a llegar. La fascinación que me produce Esquilo me impide dejarlo. Jamás pensé que iba a hacer Los Persas o Las Suplicantes. No tener la obra completa de Esquilo es una gran desgracia. Es de una gran actualidad. Las Suplicantes es un panfleto feminista que defiende los derechos de la mujer en la Grecia Clásica.

Casablanca lee a Esquilo desde procedimientos poéticos contemporáneos que religan con lo ancestral:

La tragedia de Esquilo permite trabajar con procedimientos minimalistas: la repetición, lo cíclico, la continuidad, la música reiterativa. Por eso siempre trabajo musicalmente con Philip Glass, con [J. S.] Bach o con el recorte de secuencias musicales de clásicos, cortadas y repetidas. La repetición es fundamental porque tiene que ver con las danzas ceremoniales. El trance se logra por la vía de la repetición. 


\section{TÉCNICAS Y ENTRENAMIENTO PARA EL ACTOR CREADOR}

Resulta revelador conocer cómo Casablanca concibe el entrenamiento del actor y las técnicas interpretativas que deben adquirirse y practicarse para representar los textos de Esquilo:

Contacto del actor con las grandes energías hieráticas o naturales, de concentración profunda. El actor atraviesa caminos de lava o lagos de aceite hirviendo, cascadas, grandes montañas, fieras heridas. Los grandes viajes internos del actor, en los que está concentrado sobre sí mismo y desvinculado del espectador. El actor en vínculo con Dios, con el cielo. El espectador observa algo que está pasando ahí entre el actor y los dioses. No hay comunicación directa con el espectador. Son energías extra-cotidianas. El actor mira del horizonte hacia arriba, porque con esta energía, si mirás de frente a un espectador, lo pulverizás. Lo ponés en una zona de incomodidad absoluta, más si se trata de una sala independiente de pequeña dimensión. La tragedia se hacía en teatros grandes como estadios de fútbol. La tragedia es muy formal. Todo debe ser bello y potente.

Esquilo reclama un actor sin los comportamientos cotidianos: tiene poca movilidad, movimientos económicos pero muy importantes. Un giro de cabeza puede tener una importancia enorme. Coros de canto, de movimiento y coros energéticos. Ligado a la búsqueda del ritual, la concentración profunda, individual y colectiva. Prometeo puede convertirse en un coro de cuatro Prometeos, pero para el tema del héroe hace falta valorar un figura individual. La entrada del héroe, la caída del héroe. Darío regresando de la muerte no puede ser sino una figura individual.

Actuar los textos de Esquilo exige desprenderse de los saberes de otras técnicas y métodos actorales.

A diferencia del teatro contemporáneo, las tragedias de Esquilo son textos inabarcables desde tu experiencia personal. No se puede apelar a la memoria emocional o al propio pasado. Me interesa investigar entonces cómo estos personajes pueden llegar a la emoción y no quedar fríos. Lo rígido tiene que conmover. Debo tener muy en cuenta que el espectador está una hora y media viendo al actor afectado por esas energías.

Puesto a reivindicar modelos de trabajo actoral, Casablanca explicita su deuda con Jacques Lecoq:

Me formé con el método Lecoq y lo siento como un pensamiento cercano. Pero mi trayectoria de trabajo en el actor creador me da una diferencia. Las reglas básicas de la tragedia vienen de Lecoq y las conocí a través de [Cristina] Moreira. Energías grandilocuentes, alejadas de lo cotidiano, 
movimiento escénico muy formal y cuidado, mirada desde el horizonte hacia arriba, no comunicación directa con el espectador, síntesis en los movimientos, protagonismo del texto, presencia de los elementos: agua y fuego, así como el trabajo con la belleza, el volumen, el aroma de los elementos (uso de sahumerios); códigos de síntesis (unidad) y de alteridad (diferencia con la vida común).

Casablanca piensa su relación con Lecoq a partir de su peculiar idea del "actor creador". No se trata de un "lecoquismo" ortodoxo, sino heterodoxo, híbrido, nueva apropiación -como la esquileana- desde otra territorialidad e historicidad, desde otra experiencia actoral.

Es un concepto más ideológico que de formación técnica-actoral. Es una contraposición al concepto de actor instrumento. El actor instrumento es el actor entrenado, técnicamente funcional, al servicio de un director o autor o productor, al servicio de un discurso que no le es totalmente propio y en algunos casos no lo representa. Un actor mercenario. Por el contrario, un actor creador entrena y va acumulando los conceptos teóricos de la técnica a medida que transita con su cuerpo la experiencia física-expresiva, y tiene la posibilidad él mismo de recuperar, 'repetir', palabra básica en el hecho teatral. Recuperar un ejercicio sin necesidad de una voz exterior (director o docente) que repita la consigna. La consigna en el primer ejercicio debe ser clara y precisa, una orden concreta que pone al cuerpo en movimiento para que el actor deje de pensar y sea expresión en el espacio. Esa orden se convierte en un estímulo directo, una energía (calidad de movimiento), acompañada a veces por un recurso técnico, límite para desarrollar y aprovechar de maneras distintas esa calidad de movimiento que de esta manera se convierte en máscara. Si la consigna en el primer ejercicio fue clara y precisa, la repetición del ejercicio será la apropiación del recurso. En una segunda y tercera repetición, el actor es dueño de esa orden técnica. Esta experiencia le permite aplicar lo aprendido con otra mirada, conocimiento teórico-práctico de la experiencia. En la medida que se suman ejercicios aumenta el discurso técnico del actor, que puede empezar a combinar recursos enriqueciendo su lenguaje expresivo. Puede evaluar, puede dialogar con sus pares y puede modificar desde su propio discurso técnico el próximo paso. Tiene las herramientas técnicas para modificar el futuro. Esta repetición es el ensayo. El ejercicio que muere súbitamente en su primer intento puede ser muy efectivo, divertido, relajado para el actor, que en cero sólo recibe órdenes de afuera. Pero ese ejercicio sin repetición no asegura la concientización de ese material. No asegura el aprendizaje. Sólo será entrenamiento de un cuerpo expresivo, elongación de la expresión. Falta el 50\% de trabajo, la apropiación de los códigos, que el actor disponga de todos estos recursos y en las combinaciones que él solo imagine para volver a probar y arriesgar. Estas repeticiones lo llevan irremediablemente a un trabajo de puesta. Un actor 
comprometido desde la actuación con todo lo que encierra al hecho teatral: 1. la orden básica para que el cuerpo arranque; 2 . los recursos, vías para el tránsito de ese cuerpo en movimiento (nacimiento de la máscara); 3. objetos o elementos que respondan a los movimientos de esta máscara (acciones); 4. la imagen (el texto no dicho: vestuario, música, luz). El texto no dicho funciona directamente con la expresión del cuerpo. Un vestuario puede fortalecer el personaje y permitirle al actor disminuir el volumen expresivo para subrayar o contraponer lo que el cuerpo está haciendo. Todo esto sobre el tapete hace a un actor creador.

Para Casablanca, los objetivos del género tragedia son la concentración profunda y el "viaje del actor", que implican un recorrido, en el que se pone en juego "la energía de los elementos, de los animales, de los témpanos, del árbol. Son energías de larga duración, acordes con los textos de Esquilo, de intensidad sostenida”. Le pedimos que desarrolle algunos ejemplos:

El árbol: me concentro, apoyo la planta de los pies, los pies se aferran al suelo como raíces, siento que circula la sabia por todo el cuerpo, las manos se convierten en las ramas. Energía de poco movimiento pero muy potente porque toma la energía de la tierra. Y el árbol, que es un cero trágico, un neutro trágico, sufre brisa, viento y tormenta.

El vientre materno: el agua tibia, cerrada, fetal, pequeña, de nivel bajo, va hacia un lago, que es más fresco, y el lago se convierte en rápido y éste desemboca en el mar y termina siendo Poseidón.

El fuego: un carbón, una brasa, la chispa, el fuego.

Esas energías se usan en los entrenamientos y durante los espectáculos. La presencia de estas energías garantiza que no se torne un material puramente formal, que no pierda vida. Hay que decir el texto desde estos estados puros de juego físico. El actor se puede divertir haciendo tragedia, no tiene por qué estar sufriendo. Juego a subirme al caballo alado y volar: desde esa situación interna digo el texto. Esos juegos se recuperan de función a función.

Le preguntamos entonces por sus diferencias con Lecoq y Moreira y Casablanca asevera:

Es que ellos trabajan con estas calidades o títulos pero aseguran que hay un resultado formal lógico al que hay que llegar, vienen del mimo y de la danza. A mí me interesa como cocina interna del actor, no busco un resultado formal especial. El método Lecoq peca de demasiada formalidad expresiva en sus finales. Hay una manera de que se hagan las cosas. Para mí estas energías son estímulos: después el actor llega a un objetivo con eso. Lo importante es que técnicamente lo pueda recuperar siempre que quiera. La calidad del juego va a ser arrítmica porque el juego así lo propone. 


\section{De Prometeo encadenado a Prometeo (2002-2003)}

Indagamos a Casablanca en torno de los procesos de trabajo sobre Prometeo encadenado, primera de sus reescrituras estrenadas ${ }^{5}$.

Tomamos como base de traducción la edición de Gredos, confrontada con otras traducciones que aportan lectura e interpretaciones muy diferentes. Usamos un vocabulario actualizado pero no localizado en Buenos Aires. En el texto no hay indicaciones de cómo ponerlo en escena, pero es porque la buena obra no las necesita. Encarné a Prometeo en cuatro actores porque Prometeo podía estar en más de un lugar a la vez.

Prometeo es el prototipo del superhombre que peca. Es el primero en todo. Es castigado (como en el pecado original) por informarse. Queda apresado por dar el fuego a los hombres. La imagen del castigo era sintetizada con una máscara.

Según parece el texto que conservamos es la segunda parte de la trilogía trágica. Como se ha perdido la primera parte, pensé: el principio es el principio, y busqué textos vinculados al origen cosmogónico del mundo y del hombre, el nacimiento del hombre y de las cosas. Recreamos en una escena el Popol-Vuh y hacíamos un hombre de arcilla, ante los ojos de los espectadores. También remitimos al Génesis, 'En el principio fue el Verbo', y trabajábamos todo el comienzo en la oscuridad. Alejandro Zanga era el Prometeo principal y a la vez la voz del Popol-Vuh y del Génesis. Ropa de taller, lugar ochentoso, de fábrica. Hermes: herrero.

El de Prometeo fue mi primer elenco grande y eso me impulsó a trabajar con un solo texto completo (antes trabajaba con fragmentos, un collage, que incluía fragmentos de Sófocles y Eurípides). El personaje de Io también aparecía en tres actrices con el mismo vestuario. La razón es sencilla: tenía que trabajar con tres actrices. En algunos casos el desdoble funciona y en otros no.

Hicimos un entrenamiento de percusión con César Lerner y nos pareció que lo mejor que entraba eran los tachos grandes. El uso de grandes timbales estaba en la época: Stomp, El Choque Urbano. Se suma la atemporalidad de la sala del IFT, una caverna. Prefiero la sala de cámara para la tragedia y los espacios no convencionales o los naturales, al aire libre.

\section{¿Por qué Prometeo en la primera experiencia de dirección de Esquilo?}

Es un texto con el que vengo trabajando desde siempre. El lamento de Prometeo encadenado es de una belleza absoluta. Me fascina su prepotencia, su arrogancia de no aceptar la negociación con Zeus. Es el gran momento, la gran decisión de Prometeo. La secuencia de interés es: Prometeo sabio, el

${ }^{5}$ Conservamos un video de la puesta en escena en el IFT (2002) en nuestro archivo, por gentileza de Daniel Casablanca. 
que descubre el fuego y lo roba, el encadenado. Sumamos al texto unos versos de Juan Goytisolo ("Palabras para Julia"), que le dicen a Prometeo cuando lo encadenan; y una canción tradicional de José Luis Castiñeira de Dios con su grupo Anacrusa: 'No me río de la muerte', folclore anónimo argentino. También incorporamos Bach. En un espectáculo anterior trabajamos la $\mathrm{Pa}$ sión según San Mateo con ejecutivos, se les abrían los maletines, uno de ellos era crucificado y se decía el lamento de Prometeo.

¿Cómo fue el entrenamiento y las técnicas actorales en aquella primera experiencia?

En el caso de Prometeo trabajamos con la fiera herida atacada por la espalda, el árbol huracanado que no sufre el huracán sino que lo resiste, el témpano y con el mar agitado (Poseidón). Llevo baldes de hielo y los actores hacen la energía con el hielo en la mano. Trabajo con sufrir el hielo -algo humano, melodramático- y convertirse en el hielo, que es mucho más hierático: el héroe no sufre. No hay una energía constante, sino momentos. Es como un trabajo de guión cinematográfico: el actor tiene una disponibilidad de energías y trabaja cada momento con una energía diferente.

Devenir de energías en Prometeo: peca y pasa por una alegría cuando le da el fuego a los hombres; eso va a terminar en un desastre, pero está contento; el momento de mayor furia es cuando habla con Hefesto. Hefesto corta carne y la cocina: mediación y delegación de la tortura a un campo simbólico. Traducir la violencia. El muñeco de barro, la carne, el yunque, la máscara como cárcel y cadenas, funcionan como delegaciones simbólicas.

El testimonio de Daniel Casablanca sobre su relación con la tragedia esquileana devela aspectos fundamentales de su apropiación heterodoxa, desprejuiciada y transformadora, tanto en la estructura de su poética como en las formas de trabajo creativo y la concepción. ¿Cuánto hay en su poética del Esquilo histórico? Poco importa. El eje comparatista privilegia la perspectiva de la reescritura y el ejercicio contrastivo del pasado con las nuevas coordenadas de un artista singular desde Buenos Aires en el siglo XXI. A través de los siglos y de innumerables mediaciones, Casablanca construye su propio Esquilo y, al mismo tiempo y más allá de las diferencias, opera como intermediario de la presencia del gran trágico en el presente del teatro argentino. 


\section{Bibliografía}

Dubatti, J. (coord.) (2002), El nuevo teatro de Buenos Aires en la postdictadura (19832001). Micropoéticas I. Buenos Aires: Ediciones del Instituto Movilizador de Fondos Cooperativos, Centro Cultural de la Cooperación.

Dubatti, J. (coord.) (2003), El teatro de grupos, compañias y otras formaciones (19832002). Micropoéticas II. Buenos Aires: Ediciones del Instituto Movilizador de Fondos Cooperativos, Centro Cultural de la Cooperación.

Dubatti, J. (coord.) (2006), Teatro y producción de sentido político en la postdictadura. Micropoéticas III. Buenos Aires: Ediciones del Centro Cultural de la Cooperación.

Dubatti, J. (2010), Filosofía del teatro II. Cuerpo poético y función ontológica. Buenos Aires: Atuel.

Dubatti, J. (2014), Filosofía del Teatro III. El teatro de los muertos. Buenos Aires: Atuel.

Dubatti, J. (2015), "La escena teatral argentina en el siglo XXI. Permanencia, transformaciones, intensificaciones, aperturas", in Luis Alberto Quevedo (comp.), La cultura argentina hoy. Tendencias! Buenos Aires: Siglo Veintiuno Editores y Fundación OSDE, 151-196.

Esquilo (1982), Tragedias. Traducción y notas de B. Perea Morales, introducción general de F. Rodríguez Adrados, revisión de B. Cabellos. Madrid: Gredos.

Kott, J. (1987), The Eating of The Gods. An Interpretation of Greek Tragedy. Illinois: Northwestern University Press.

Lecoq, J. (2003), El cuerpo poético. Una pedagogía de la creación teatral. Barcelona: Alba Editorial.

Macocos Banda de Teatro (2002), Teatro deshecho I. Flora y fauna de la creación macocal. Buenos Aires: Editorial Atuel. Incluye Macocos, adiós y buena suerte, Macocos Geometría de un viaje, La fabulosa historia de los inolvidables Marrapodi y Los Albornoz (Delicias de una familia argentina). Estudio preliminar (5-51) y edición al cuidado de J. Dubatti.

Moreira, C. (2010), Las múltiples caras del actor. Buenos Aires: Instituto Nacional del Teatro. 